\title{
Considerations about heart rate variability in leukemia
}

\author{
Vitor E. Valenti ${ }^{1} \cdot$ Jociele M. Kirizawa ${ }^{1} \cdot$ David M. Garner $^{1,2} \cdot$ Claudia Arab $^{3}$ \\ Received: 31 October 2019 / Accepted: 20 November 2019/Published online: 28 November 2019 \\ (C) Springer-Verlag GmbH Germany, part of Springer Nature 2019
}

We read the letter by Caru and Curnier [1] with concerns that related to our recent manuscript published in Supportive Care in Cancer [2]. We are delighted to know that the authors carefully read our systematic review that intended to investigate the use of heart rate variability (HRV) in leukemia subjects.

1. We absolutely agree with the authors that "systematic reviews provide one of the highest forms of evidence to answer healthcare questions." Nevertheless, the authors indicated that our study was not up-to-date since a recent article was published on February 18, 2019 [3]. However, and unfortunately, we specified in our Methods section that the review was valid up to March 2018. Our methods description clarifies all procedures performed and the fact mentioned by the authors does not impair the reproducibility of our study. We are sure that the abovementioned study [3] would add further relevant content to the published review [2] and scientific community.

2. It is completely apparent to us that physical exercise is a non-pharmacological intervention that improves autonomic dysfunction in cancer patients. Our group published a previous systematic review that provides information regarding this point [4]. Nonetheless, no previous study has investigated the effect of physical exercise on HRV in subjects with leukemia. Therefore, it is not in accordance with our systematic review a topic related to exercise and cancer, as we focused on leukemia.

Vitor E. Valenti

vitor.valenti@unesp.br

1 Autonomic Nervous System Center, UNESP, Av. Hygino Muzzi Filho, 737, Mirante, Marilia, SP 17525-900, Brazil

2 Cardiorespiratory Research Group, Department of Biological and Medical Sciences, Faculty of Health and Life Sciences, Oxford Brookes University, Headington Campus, Gipsy Lane, Oxford OX3 0BP, UK

3 Department of Medicine (Cardiology), Federal University of São Paulo (UNIFESP), Sao Paulo, Brazil
3. The increased risk for cancer survivors to develop cardiovascular disorders is unequivocally a significant development for the clinical team. However, it lacks this information in individuals with leukemia in association with HRV (until 28th of March 2018). Consequently, including such an issue in our review would confuse the reader, as it is not in the scope of our systematic review.

We acknowledge this opportunity to discuss this globally implemented technique in this important journal and we are available to answer any concerns regarding our study.

\section{Compliance with ethical standards}

Conflict of interest The authors declare that they have no conflict of interest.

\section{References}

1. Caru M, Curnier D (2019) Letter to the Editor: Re: "Is heart rate variability a valuable method to investigate cardiac autonomic dysfunction in subjects with leukemia? A systematic review to evaluate its importance in clinical practice" by Kirizawa et al. Support Care Cancer:1-2. https://doi.org/10.1007/s00520-019-05103-6

2. Kirizawa JM, Garner DM, Arab C, Valenti VE (2019) Is heart rate variability a valuable method to investigate cardiac autonomic dysfunction in subjects with leukemia? A systematic review to evaluate its importance in clinical practice. Support Care Cancer. https://doi. org/10.1007/s00520-019-05047-x

3. Caru M, Corbin D, Perie D, Lemay V, Delfrate J, Drouin S et al (2019) Doxorubicin treatments induce significant changes on the cardiac autonomic nervous system in childhood acute lymphoblastic leukemia long-term survivors. Clin Res Cardiol 108:1000-1008. https://doi.org/10.1007/s00392-019-01427-9

4. Arab C, Dias DP, Barbosa RT, Carvalho TD, Valenti VE, Crocetta TB, Ferreira M, Abreu LC, Ferreira C (2016) Heart rate variability measure in breast cancer patients and survivors: a systematic review. Psychoneuroendocrinology 68:57-68. https://doi.org/10.1016/j. psyneuen.2016.02.018

Publisher's note Springer Nature remains neutral with regard to jurisdictional claims in published maps and institutional affiliations. 